\title{
Effect of Tramadol Abuse on Male Fertility
}

\author{
Aya A. Saadeldin ${ }^{a^{*}}$, Al Shaimaa Hasan ${ }^{a}$, Mohammed H. Hassan ${ }^{\text {, }}$, Gamal A. Alsagheer

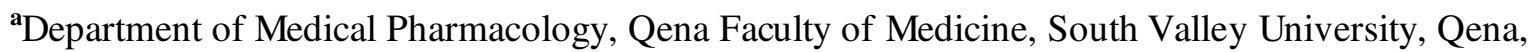 \\ Egypt. \\ ${ }^{\mathbf{b}}$ Department of Medical Biochemistry, Qena Faculty of Medicine, South Valley University, Qena, Egypt. \\ ${ }^{\mathfrak{c}}$ Department of Urology, Qena University Hospital, South Valley University, Qena, Egypt.
}

\begin{abstract}
Background: Addiction is still an increasingly social and health issue worldwide, despite all attempts to overcome it. Analgesics are of the most prevalent substances that are abused. In Egypt and the Middle East, tramadol abuse is highly increasing. This can be correlated to its inexpensive cost, large availability, accessibility and illegal trafficking. Tramadol is a centrally-acting synthetic opioid analgesic that is commonly used to treat different intensities of pain varying from mild to extreme pain conditions. Prolonged administration of tramadol can result in abnormalities of the hypothalamic-pituitary function and decrease in testosterone production. Many experimental studies were done and showed that tramadol affects the level of luteinizing hormone, follicular stimulating hormone, testosterone, estradiol, and prolactin. It also affects sperm quality and motility.

Objectives: We aimed in this review to delineate these issues.

Conclusion: There is a significant correlation between tramadol abuse and impaired gonadal and male sex hormone and sperm quality parameters.

Keywords: Tramadol, Tramadol Abuse, Fertility.
\end{abstract}

\section{Introduction:}

\section{- Pharmacology of Tramadol}

\section{Tramadol Pharmacokinetics}

Tramadol is a synthetic opioid drug that is centrally acting. Capsules and tablets are easily available worldwide and are the most widely used formulations (Scott and Perry, 2000).

After administration of oral single dose of tramadol, its bioavailability is about $70 \%$. Its volume of distribution is nearly $306 \mathrm{~L}$ with plasma protein binding capacity up to $20 \%$. The effective plasma concentration of tramadol is within range of 100-300 $\mu \mathrm{g} / \mathrm{L}$. Half-life of plasma elimination of tramadol is about $6 \mathrm{~h}$ (Barakat, 2019).
$\mathrm{N}$ - and O-demethylation reaction and conjugation reaction are the primarily metabolic reactions involved in the metabolism of tramadol. The main effective analgesic metabolite of tramadol M1 is obtained by tramadol O-demethylation and this reaction is catalyzed by cytochrome P450 (CYP) 2D6, while CYP2B6 and CYP3A4 catalyse N-demethylation of tramadol to M2 (Ardakani et al., 2018). The rate of tramadol metabolism is controlled by capacity of the P450 enzyme system. Tramadol is primarily excreted by the kidneys about either in the unchanged form or in the metabolized form. It is also

Copyright: () Saadeldin et al. (2021) Immediate open access to its content on the principle that making research freely available to the public supports a greater global exchange of knowledge. Users have the right to Read, download, copy, distribute, print or share link to the full texts under a Creative Commons BY-NC-SA 4.0 International License. 
excreted by the fecal route (Vazzana et al., 2015).

\section{Tramadol Pharmacodynamics}

Tramadol exhibits mono-aminergic effects comparable to serotonin norepinephrine reuptake inhibitors. Tramadol produces analgesia by influencing the nociceptive mechanism and enhancing central pain modulation (Power,2011).It exhibitsa poor affinity for the $\mu$-opioid receptors (Grond and Sablotzki, 2004).The agonistic activity of the $\mu$-opioid receptor in tramadol is about 10 times lower than codeine. Even so, in comparison with the parent drug, M1 metabolite of tramadol exhibits 300 times more affinity for the $m \mu$ receptor (Benzon, 2013).

Tramadol is most commonly used for palliation of different acute and chronic pain complaints such as neuropathic pain, osteoarthritis, refractory restless leg syndrome (Silber et al., 2018), low back pain (Chaparro et al., 2013), and rheumatoid arthritis (Whittle et al., 2011). The proof for its effectiveness in the management of postoperative pain is ambiguous (Kubota et al., 2008); however adding analgesics other than opioid can improve the response. Moreover, tramadol has been used as an on-demand therapy for improving premature ejaculation (HamidiMadani et al., 2018) and suggested for the palliation of different disorders of opioid use (Sarkar et al., 2012).

Tramadol exhibits a well-tolerated adverse effects most frequently nausea, vomiting, sweating, and dry mouth. Also, Dizziness, drowsiness and exhaustion were recorded (Grond and Sablotzki, 2004). Diarrhea and cardiovascular problems were recored as less commonly occurring adverse effects (WHO 2018). It has been reported that there is a relationship between tramadol use and seizures and suicide attempts (Marincsák et al., 2008).Anger, hostility, and aggressive behavior were reported with chronic tramadol abusers(Minami et al., 2011).

\section{Tramadol Overdose and Toxicity}

Lethargy, fatigue, restlessness, seizures, respiratory depression, coma, and serotonin syndrome are associated with tramadol overdose. The toxicity of tramadol overdose is not found to be lethal (Barakat, 2019).

\section{Tramadol Abuse}

Premised on the idea that the risk of tramadol abuse was minimal and did not validate a scheduled status, Tramadol was approved as a non-scheduled drug. (Cicero et al., 2005). The insufficient product labeling and lack of a proven potential for abuse led many clinicians to feel safe to prescribe it. As a result, multiple reports have been received of abuse and dependency (Fawzi, 2011).

Using the Mood Rating Scale, tramadol improves the reward system and stimulates feelings of contentment, relaxation, and friendliness, and also enhanced domains of alertness versus placebo. It has the ability to trigger abuse and/or dependency (Asari et al., 2018).Also, the increase of tramadol availability has resulted in an increase in its diversion and abuse. So it is 
categorized as a Schedule IV substance in 2014 (Miotto et al., 2017).

A national survey of Substance Use Disorders in Egypt revealed that tramadol is included among the most commonly abused drugs (Hamdi et al., 2013). In Egypt, the abuse of tramadol is fairly widespread due to its low price, accessibility and availability. The patients can quickly obtain tramadol from drug dealers and traffickers. Abuse of tramadol has increased considerably in the Middle East, particularly in Egypt (Bassiony et al., 2016).

\section{Tramadol Dependence}

With regards to the potential for tramadol dependency, animal experiments found that tramadol may cause physical dependence and mild symptoms of withdrawal but this was not documented in all studies (Cha et al., 2014). Human research showed that the risk of dependency was low relative to morphine (Epstein et al., 2006).

Tramadol dependence is at the peak of all abused substances abused in Egypt, at $49 \%$. Tramadoldependence in males is more common than in females and more prevalent in young people than in the elderly (Mohamed et al., 2015).Egypt's national authorities agree that tramadol regulation have to be expanded and more restrictive measures have to be applied to control and limit its availability because of the deleterious effects of substance abuse (Klein, 2019).

\section{Tramadol Withdrawal}

Sudden termination of tramadol intake in either tramadol abusers or patient taking it as a therapy may lead to notable opioid and serotonin norepinephrine reuptake inhibitors-related withdrawal symptoms. Common opioid symptoms include myoclonus, agitation, depressive manifestations, anxiety, sweating, trembling, restlessness, uncontrolled muscular movements, tremors, and gastrointestinal tract related symptoms. Atypical serotonin norepinephrine reuptake inhibitors -like withdrawal symptoms include restless leg syndrome, significant anxiety, psychosis, panic attacks, unusual sensory phenomena, and hallucinations (Miotto et al., 2017).

\section{Tramadol and Male Fertility}

Prolonged administration of tramadol has adverse impacts on many body tissues like hepatic tissue, renal tissue, thyroid gland (Hafez et al., 2015), and testicular tissue (ElSawyand Malak, 2015).

In an experimental study, rats were subjected to subcutaneous injections of tramadol at a dose that approximately equivalent to oral dose of human for a duration of eight weeks. Lower luteinizing hormone, and follicular stimulating hormone, and higher prolactin levels were developed by treatment with tramadol (Ahmed and Kurkar, 2014). Drug-induced rat hyperprolactinemia at a dose that did not have a negative effect on total testosterone, estradiol, or inhibin levels have led to decrease in luteinizing hormone and follicular stimulating hormone levels, 
abnormal testicular histology, irregular acrosomal structure and morphology, and increased fragmentation of DNA (GillSharma et al., 2003).

Semen quality can be also influenced in the form of disruption of various seminal parameters such as reduction of total sperm count, concentration, vitality, and motility and alteration of normal structure. Also, it has been reported that there was a direct effect of hyperprolactinemia on testicular tissues. The Leydig cells have prolactin receptors and prolactin is required for wellestablished function of leydig cell; however, prolactin can also reduce activity of luteinizing hormone receptor in these cells (Frungieri et al., 2015).

Tramadol abuse directly influences the release of luteinizing hormone and follicular stimulating hormone from the anterior pituitary gland that decreases the natural release of luteinizing hormone in a pulsatile manner, resulting in a negative impact on male testiclesdue to lower levels of testosterone hormaone (Ghowsi and Yousofvand, 2015).

Consequently, reducing testosterone levels will contribute to decreased sexual desire as well as erection maintenance. A hypothalamic-pitutary gonadal axis malfunction may also lead to widespread changes in the body, such as hypogonadism, poor libido, erectile male dysfunction, irregular menstrual cycles in women, and likely infertility in both genders men and women (Osadolor and Omo-Erhabor, 2016).
It has been documented that tramadol has a negative impact on spermatogenesis that dose-related alterations in the ultrastructure has been revealed by electron microscopy. Tramadol has been concluded to adversely affect all epididymal cells, which ultimately impaire epididymal function and can deteriorate sperm maturation, resulting in subfertility (Attia et al., 2018). The recorded changes in male rats which were subjected to tramadol could demonstrate delayed fertility and disturbance in psychological behavior associated with tramadol abuse. Tramadol increased oxidative stress in different tissues including the testicles and cerebral cortex. Both of these organs experienced increase of apoptosis (Ghoneim et al., 2014).

Studying tramadol induced histomorphological changes of the testicular tissues showed variable degrees of irregularities and degeneration in the seminiferous tubules. They displayed disorganization of spermatogenic cells including shrinkage, basement membrane isolation of the tubules, and spermatogenic layer disorganization. Vacuoles appeared between the damaged spermatogenic cells and take their place. Exfoliation of degenerated cells and darkly stained nuclei into the tubular lumen has been reported. There were a notable decrease of values of the diameter of seminiferous tubules and values of the germinal epithelial height (Abdellatief et al., 2015).

These findings were explained by tramadol's oxidative damage and free radical development, specifically on testes. This 
could be explained by presence of numerous content of polyunsaturated fatty acids in the plasma membranes of both the testicular tissues and sperms (Sayed and Zidan, 2016). Tramadol reduces the activity of the antioxidant enzyme and raise the testicular nitric oxide levels; all of these effects ultimately promote testicular tissue degeneration (Ahmed and Kurkar, 2014).

It was also postulated that these impacts of tramadol on the testicles are due to its effects on sex hormones. Plasma levels of follicular stimulating hormone, luteinizing hormone, and testosterone have been reduced, which can be ultimately responsible for the negative effects of tramadol on testicular tissues (Abou El Fatoh et al., 2014). These cellular-level toxic effects of tramadol may be explained by increasing lipid peroxidation and accumulation of reactive oxygen species, leading to cell damage (Ragab and Mohamed, 2017).

Another theory of expalanation of tramadol effects is that sertoli metabolic changes and appearance of vacuoles in between them. Sertoli cells are primarily affected by testosterone that testosterone enhances their production of androgen-binding protein and other essential compounds under the triggering action of follicular stimulating hormone. Tramadol disturbed this relation and triggered morphological changes due to deprivation of testosterone (Abdellatief et al., 2015). It is important to delineate that negative effects of tramadol on sperm production and testicular tissue are reversible and those negative impacts did not last for more than 6 weeks after drug cessation (Azari et al., 2014).

\section{Conclusion:}

There is a significant correlation between tramadol abuse and impaired gonadal and male sex hormone and sperm quality parameters.

\section{References:}

Abdellatief RB, Elgamal DA, Mohamed EE. (2015). Effects of chronic tramadol administration on testicular tissue in rats: an experimental study. Andrologia, 47(6):6749.

\section{Abou El Fatoh MF, Farag M, Sayed AE, Kamel MA, Abdel-Hamid N, Hussein M, et al., (2014). Some biochemical, neurochemical, pharmacotoxicological and histopathological alterations induced by long-term administration of tramadol in male rats. Int J Pharm Sci, 4(3):565-571.}

Ahmed MA, Kurkar A. (2014). Effects of opioid (tramadol) treatment on testicular functions in adult male rats: The role of nitric oxide and oxidative stress. Clinical and Experimental Pharmacology and Physiology, 41(4):317-23.

Ardakani YH, Lavasani H, Rouini MR. (2018). Gender Dependency in Streoselective Pharmacokinetics of Tramadol and Its Phase I Metabolites in Relation to CYP2D6 Phenotype in Iranian Population. Iranian Journal of Pharmaceutical Research: IJPR, 17(2):767. 
Asari Y, Ikeda Y, Tateno A, Okubo Y, Iijima T, Suzuki H. (2018). Acute tramadol enhances brain activity associated with reward anticipation in the nucleus accumbens. Psychopharmacology, 235(9):2631-42.

Attia AM, Bakry OA, Yassin H, Sarhan N, Samaka R, Gamal N. (2018). Morphometric and ultrastructural analysis of tramadol effects on epididymis: an experimental study. Ultrastructural pathology, 42(3):295-303.

Azari O, Emadi L, Kheirandish R, ShafieiBafti H, EsmailiNejad MR et al., (2014).The effects of long-term administration of tramadol on epididymal sperm quality and testicular tissue in mice. Iranian Journal of Veterinary Surgery, 9(1):23-30.

Barakat A. (2019).Revisiting tramadol: a multi-modal agent for pain management. CNS drugs, 33(5):481-501.

Bassiony MM, Youssif UM, Hussein RA, Saeed M. (2016). Psychiatric comorbidity among Egyptian patients with opioid use disorders attributed to tramadol. Journal of addiction medicine, 10(4):262-8.

Benzon H, Rathmell JP, Wu CL, Turk D, Argoff CE, Hurley RW. (2013).Practical Management of Pain E-Book.Elsevier Health Sciences.

Cha HJ, Song MJ, Lee KW, Kim EJ, Kim YH, Lee $Y$ et al., (2014). Dependence potential of tramadol: behavioral pharmacology in rodents. Biomolecules \& therapeutics, 22(6):558.
Chaparro LE, Furlan AD, Deshpande A, MailisGagnon A, Atlas S, Turk DC. (2013).Opioids compared to placebo or other treatments for chronic lowback pain. Cochrane Database of Systematic Reviews, (8):CD004959.

Cicero TJ, Inciardi JA, Adams EH, Geller A, Senay EC, Woody GE et al., (2005). Rates of abuse of tramadol remain unchanged with the introduction of new branded and generic products: results of an abuse monitoring system, 1994-2004. Pharmacoepidemiology and drug safety, 14(12):851-9.

El Sawy MM, Malak HW. (2015). Effect of tramadol abuse on testicular tissue of adult albino rats: a light and electron microscopic study. Egyptian Journal of Histology, 38(2):356-66.

Epstein DH, Preston KL, Jasinski DR. (2006). Abuse liability, behavioral pharmacology, and physical-dependence potential of opioids in humans and laboratory animals: lessons from tramadol. Biological psychology, 73(1):90-9.

Fawzi MM. (2011). Some medicolegal aspects concerning tramadol abuse: The new Middle East youth plague 2010, An Egyptian overview. Egyptian Journal of Forensic Sciences, 1(2):99-102.

Frungieri MB, Calandra RS, Mayerhofer A, Matzkin ME.(2015).Cyclooxygenase and prostaglandins in somatic cell populations of the testis.Bioscientifica; Reproduction, 149(4):169-180. 
Ghoneim FM, Khalaf HA, Elsamanoudy AZ, Helaly AN. (2014). Effect of chronic usage of tramadol on motor cerebral cortex and testicular tissues of adult male albino rats and the effect of its withdrawal: histological, immunohistochemical and biochemical study. International journal of clinical and experimental pathology, 7(11):7323.

Ghowsi M, Yousofvand N. (2015).Impact of morphine dependency and detoxification by methadone on male's rat reproductive system. Iranian journal of reproductive medicine, 13(5):275.

Gill-Sharma MK, Aleem M, Sethi G, Choudhary J, Padwal V, D'Souza S, et al., (2003).Antifertility effects of fluphenazine in adult male rats. Journal of endocrinological investigation, 26(4):31626.

Grond S, Sablotzki A. (2004).Clinical pharmacology of tramadol. Clinical pharmacokinetics, 43(13):879-923.

Hafez E. (2015).Parenchymatous toxicity of tramadol: histopathological and biochemical study. Journal of Alcoholism \& Drug Dependence, 3(5):1-6.

Hamdi E, Gawad T, Khoweiled A, Sidrak AE, Amer D, Mamdouh $R$ et al., (2013). Lifetime prevalence of alcohol and substance use in Egypt: a community survey. Substance Abuse, 34(2):97-104.

Hamidi-Madani A, Motiee R, Mokhtari G, Nasseh H, Esmaeili S, KazemnezhadE. (2018). The efficacy and safety of ondemand tramadol and paroxetine use in treatment of life long premature ejaculation: a randomized double-blind placebocontrolled clinical trial. Journal of reproduction \& infertility, 19(1):10-15.

Klein A. (2019).Drug problem or medicrime?Distribution and use of falsified tramadol medication in Egypt and West Africa. Journal of Illicit Economies and Development, 1(1):52-62.

Kubota R, Komiyama T, Miwa Y, Ide T, Toyoda H, Asanuma $F$ et al., (2008). Pharmacokinetics and postoperative analgesia of epidural tramadol: a prospective, pilot study. Current therapeutic research, 69(1):49-55.

Marincsák R, Tóth BI, Czifra G, Szabó T, Kovács L, Bíró T. (2008). The analgesic drug, tramadol, acts as an agonist of the transient receptor potential vanilloid-1. Anesthesia \& Analgesia, 106(6):1890-6.

Minami K, Yokoyama T, Ogata J, Uezono Y. (2011). The Tramadol Metabolite ODesmethyl Tramadol Inhibits Substance PReceptor Functions Expressed in Xenopus Oocytes. Journal of pharmacological sciences, 115(3):421-424.

Miotto K, Cho AK, Khalil MA, Blanco K, Sasaki JD, Rawson R. (2017). Trends in tramadol: pharmacology, metabolism, and misuse. Anesthesia \& Analgesia, 124(1):4451.

Mohamed NR, El Hamrawy LG, Shalaby AS, El Bahy MS, Abd Allah MM. (2015).An epidemiological study of tramadol HCldependence in an outpatient addiction clinic at Heliopolis Psychiatric 
Hospital.Menoufia Medical Journal, 28(2):591.

Osadolor HB, Omo-Erhabor JA. (2016).Effects of Tramadol on Fertility Hormones (Follicle Stimulating Hormone, Leutinizing Hormone, Prolactin, Testosterone, Estrogen and $\beta-\mathrm{HCG}$ ) in Laboratory Rabbits. Journal of Advances in Medicine and Medical Research, 14(8):1-11.

Power I. (2011). An update on analgesics. British journal of anaesthesia, 107(1):19-24.

Ragab IK, Mohamed HZ. (2017). Histological changes of the adult albino rats entorhinal cortex under the effect of tramadol administration: Histological and morphometric study. Alexandria journal of medicine, 53(2):123-33.

Sarkar S, Nebhinani N, Singh SM, Mattoo SK, Basu D. (2012). Tramadol dependence: a case series from India. Indian journal of psychological medicine, 34(3):283.

Sayed HY, Zidan AH. (2016).Histopathological and biochemical effects of acute and chronic tramadol drug toxicity on liver, kidney, and testicular function in adult male albino rats. Forensic Research \& Criminology International Journal, 1(2):41.

Scott LJ, Perry CM. (2000).Tramadol: a review of its use in perioperative pain. Drugs, 60(1):139-76.

Silber MH, Becker PM, Buchfuhrer MJ,Earley CJ, Ondo WG, Walters AS et al. (2018). The appropriate use of opioids in the treatment of refractory restless legs syndrome. In Mayo Clinic Proceedings, 93(1):59-67.

Vazzana M, Andreani T, FangueiroJ, Faggio C, Silva C, Santini A et al., (2015). Tramadol hydrochloride: pharmacokinetics, pharmacodynamics, adverse side effects, coadministration of drugs and new drug delivery systems. Biomedicine \& pharmacotherapy, 70:234-238.

Whittle SL, Richards BL, Husni E, Buchbinder R. (2011). Opioid therapy for treating rheumatoid arthritis pain. Cochrane Database of Systematic Reviews, (11):CD003113.

World Health Organization (WHO), (2018). Critical Review Report: Tramadol. Expert Committee on Drug Dependence.41st Meeting Geneva, Switzerland. 